ئالان صلاح صالح (1)، زينب عبد علي (2)

تأريخ تقديم البحث: (2021/8/5)، تأريخ قبول النشر (2021/9/9)، تأريخ النشر (2021/12/28) DOI: https://doi.org/10.37359/JOPE.V33(4)2021.1223

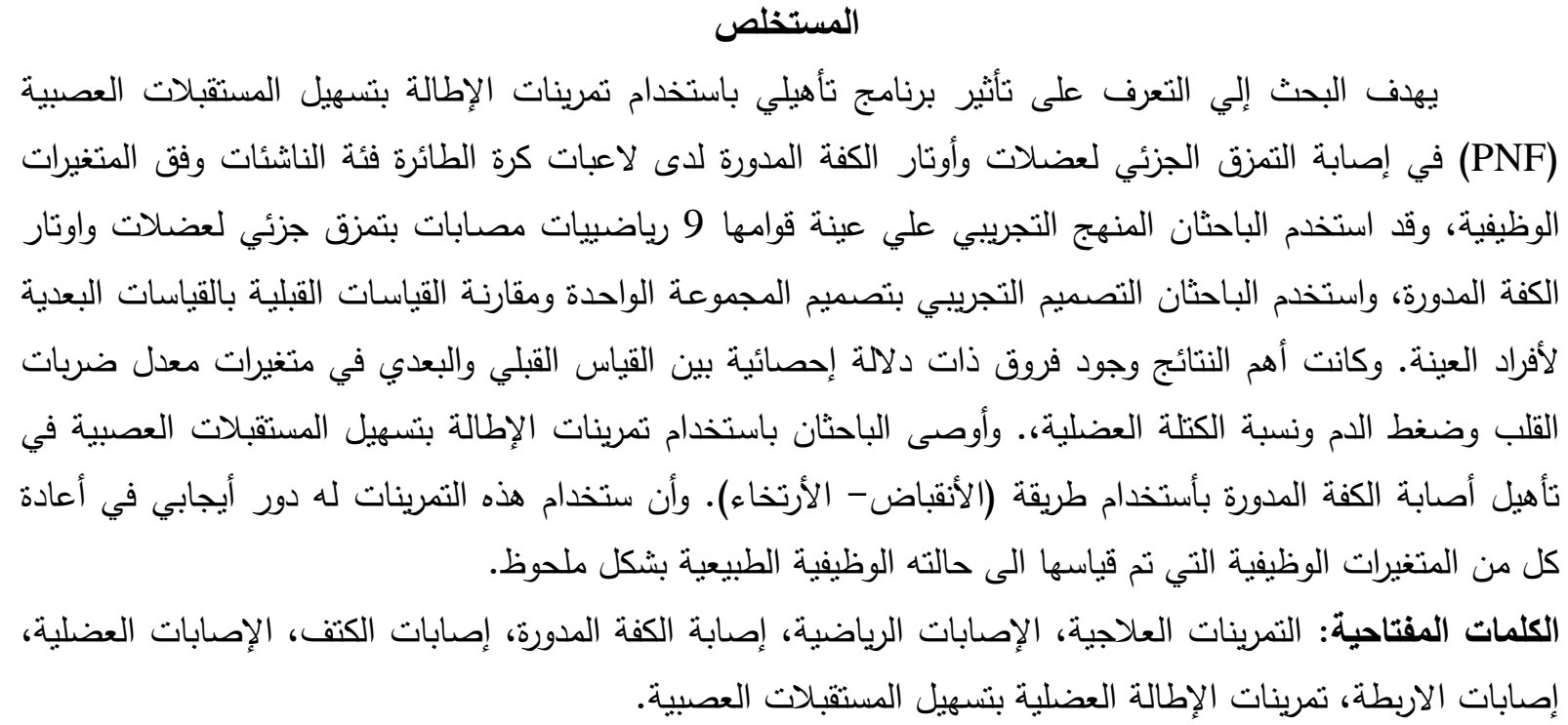

\title{
ABSTRACT \\ The Effect of Rehabilitation Program for Rotator Cuff Injury According to Functional variables in Female Volleyball Players in Sulaymania Governorate
}

The research aim at identifying the effect of rehabilitation program using stretching exercises (Proprioceptive Neuromuscular Facilitation) PNF in rotator cuff partial tear in female volleyball players according to functional variables. The researchers used the experimental method on (9) volleyball players with partial tear in the rotator cuff. They used the experimental method and the data was collected and treated using proper statistical operations to conclude significant differences between pre and posttests in heart pulse, blood pressure, and muscle mass percentage. Finally the researchers recommended using stretching to facilitated PNF in rehabilitating rotor cuff as well as using these exercises have a positive role in healing all functional variables to their normal state.

Keywords: Therapeutic exercises, sport injuries, rotator cuff injury, shoulder injury, muscular injury, stretching with PNF.

(1) طالب دراسات عليا (الدكتوراه)، جامعة السليمانية، كلية التربية البننية وعلوم الرياضة. (alan.salih@univsul.edu.iq) Alan Salah Saleh, post graduate student (PH.D), University of Sulaimani, College of Physical Education and Sport Sciences (alan.salih@univsul.edu.iq), (+9647701486442)

(2) أستاذ، دكتوراه تربية رياضية، جامعة السليمانية، كلية التربية البننية وعلوم الرياضة (zainab.abidali@koyauniversity.org). Zainab Abid Ali, Prof (PH.D), University of Sulaimani, College of Physical Education and Sport Sciences, (zainab.abidali@koyauniversity.org)(+9647701486442). 


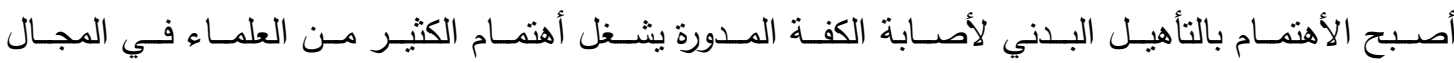

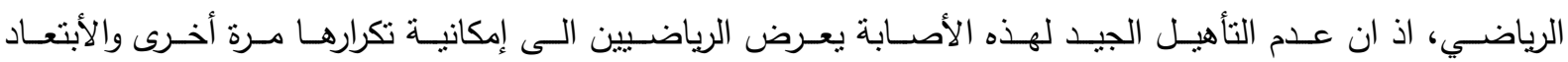
عن مزاولة اللعبة، وتضاعف الإصابة لتصل حالة مزمنة قد تحتاج إلى التذاخل الجراحي. ويشير ( Brukner and Peter, 2012, P.343) أن أصـابات مفصـل الكتف تحتـل المرتبـة الثانيـة

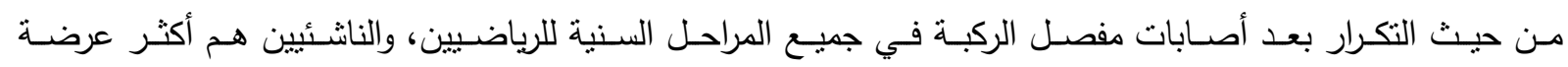

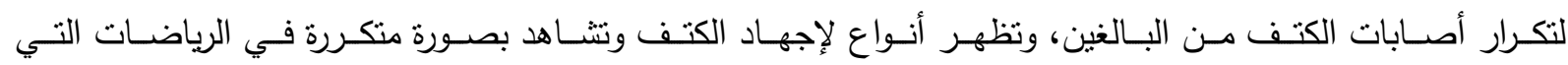

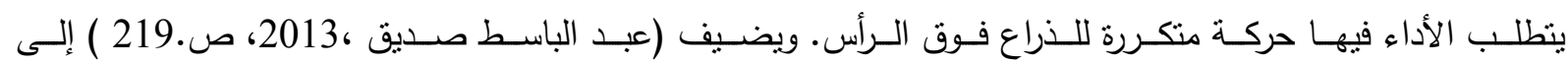

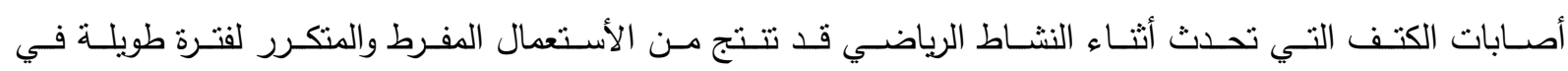

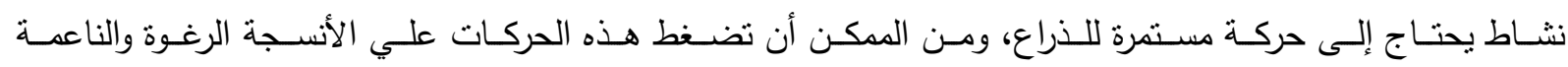

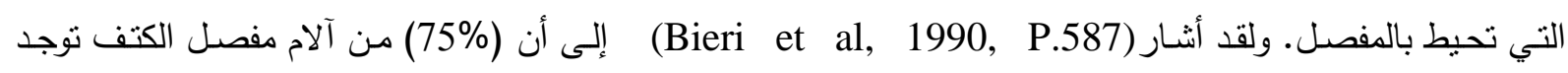

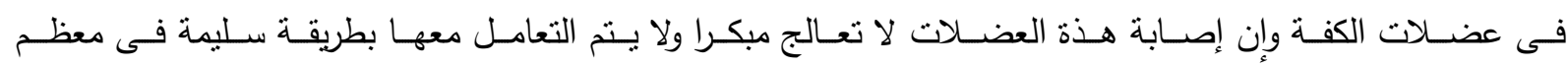

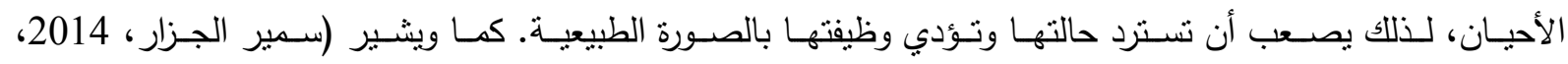

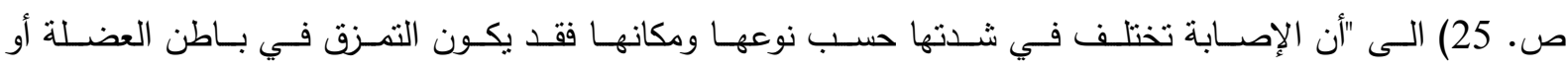

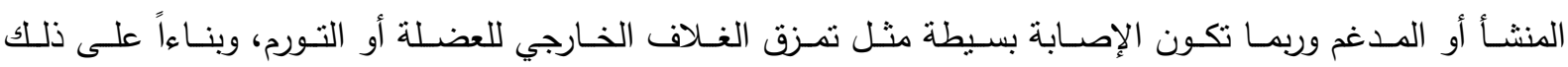

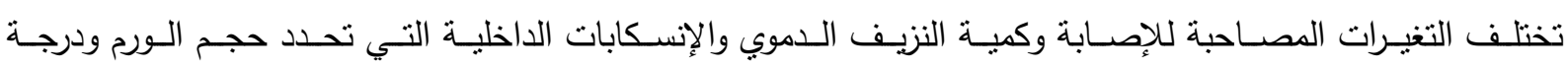

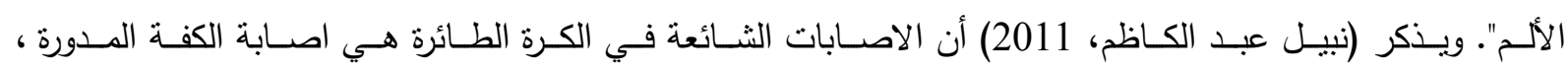

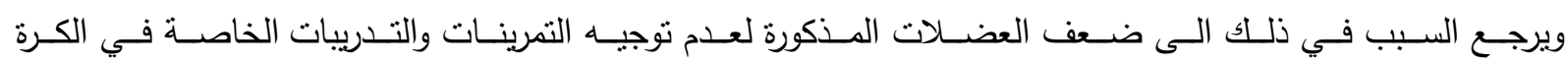

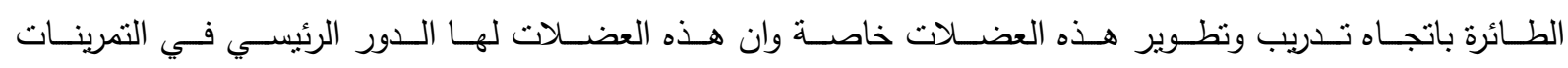

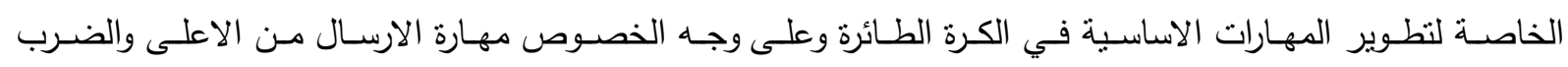

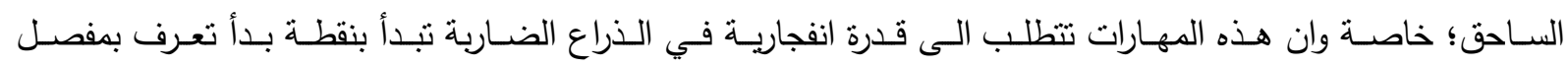

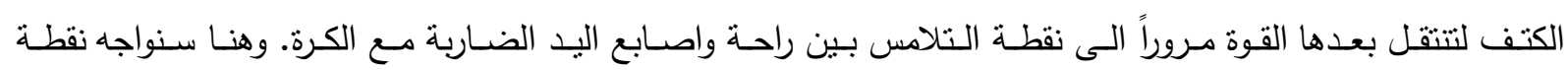

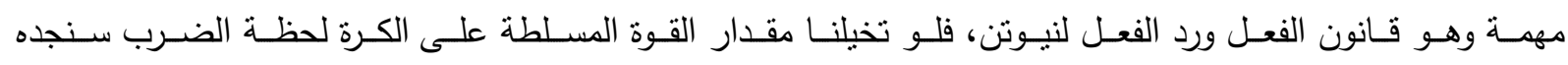

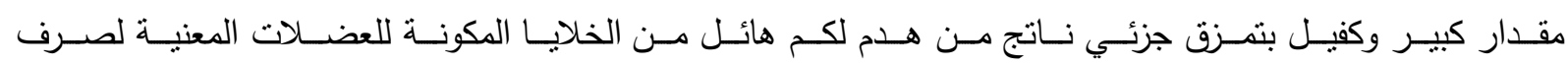

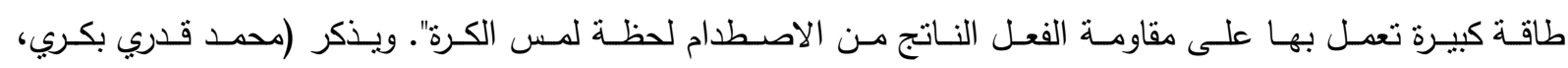

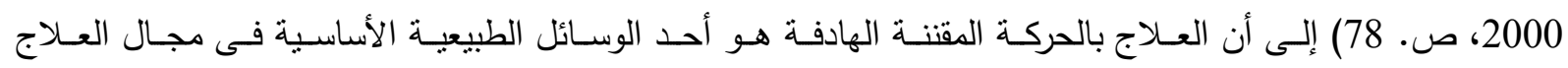

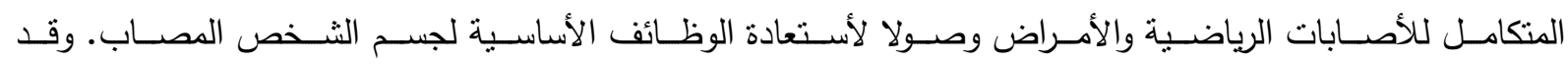

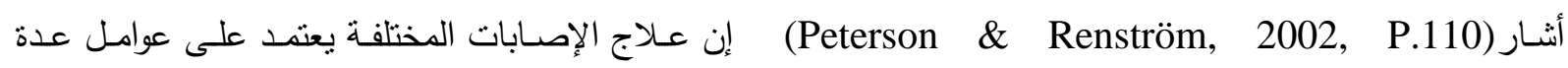

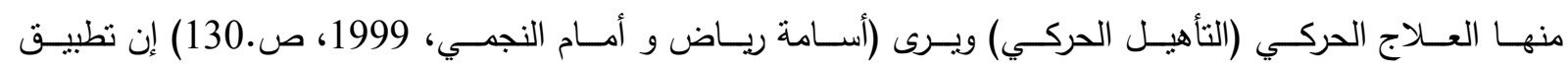

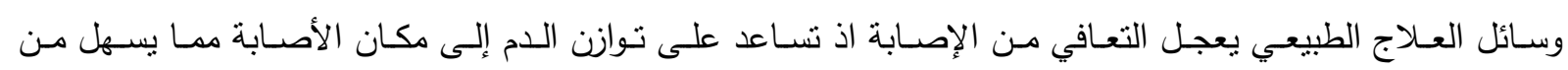

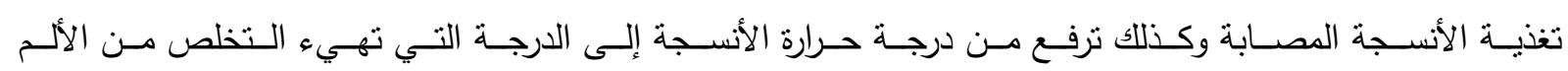

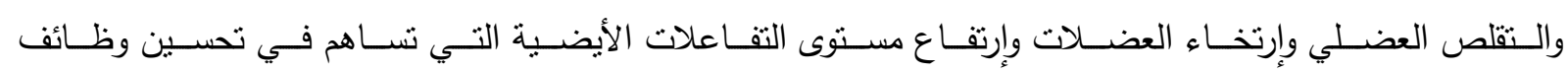
الأنسجة.

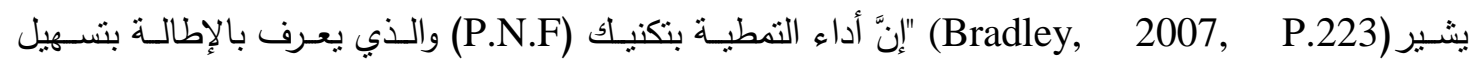

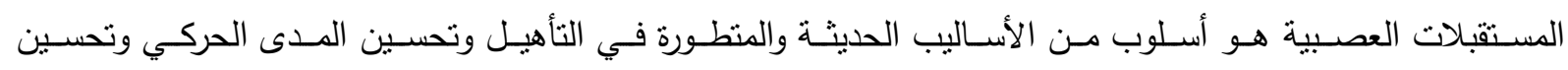

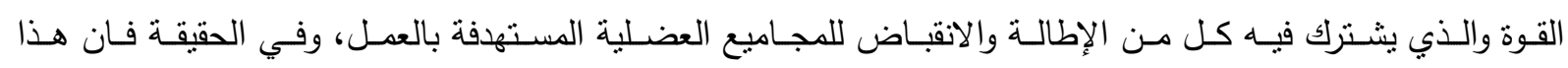




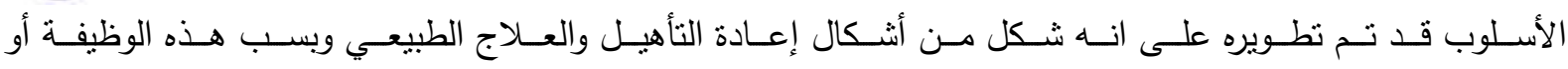

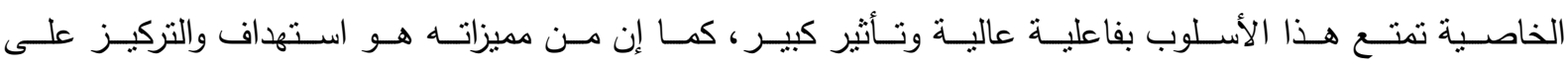

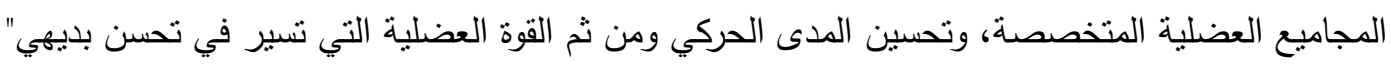

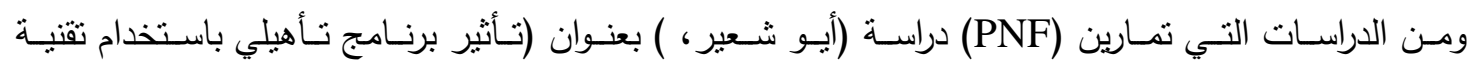

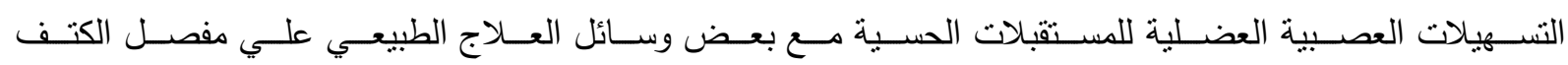

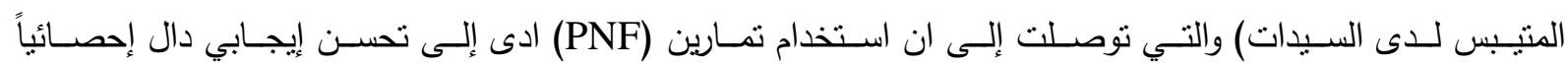

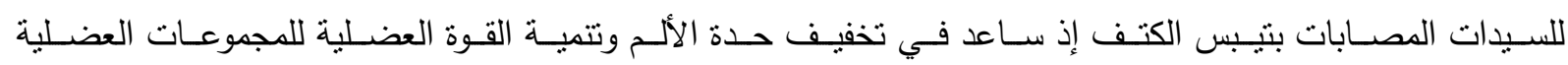

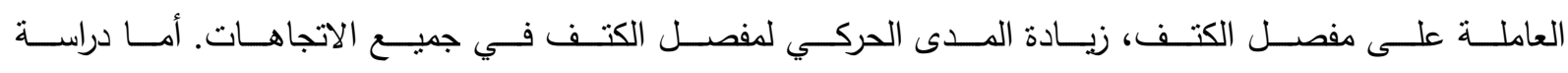

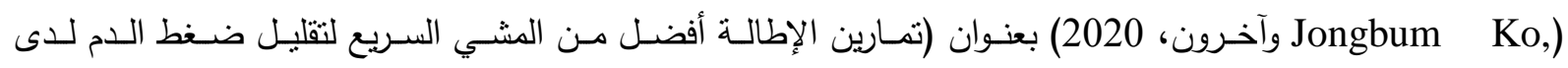

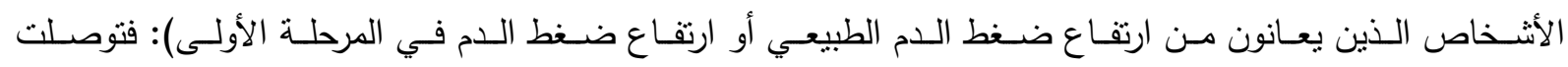

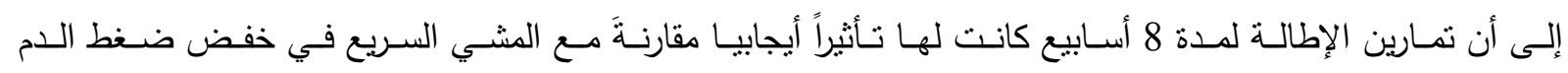

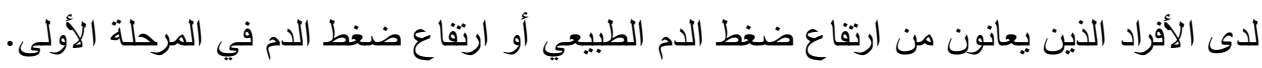

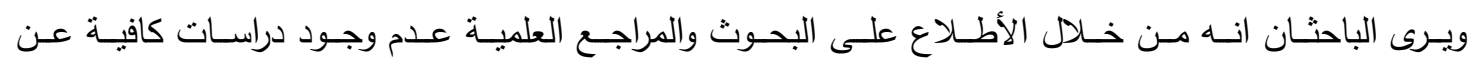

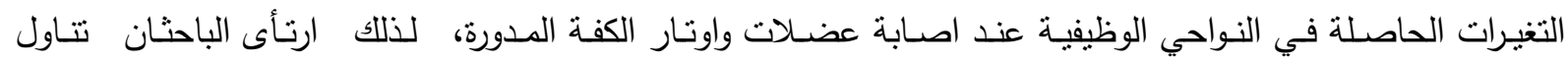

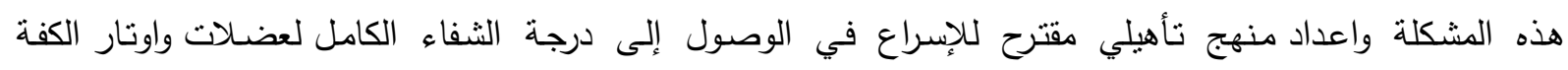

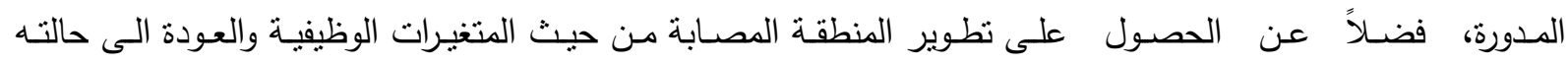

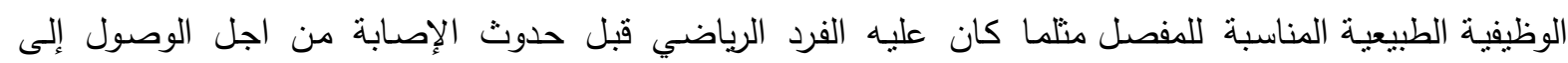
النسبة الأكبر في تحقيق النجاح في علاج هذه الإصابة.

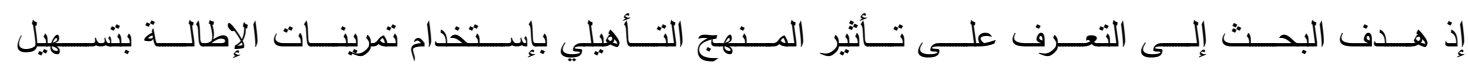

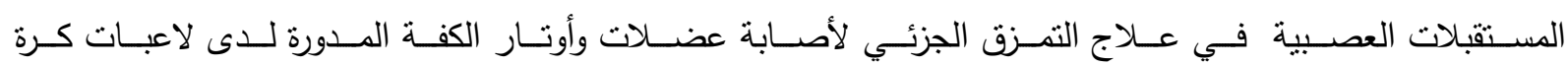
الطائرة.

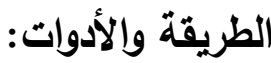

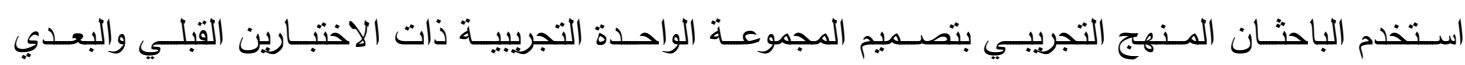

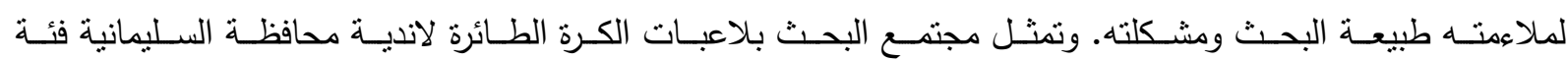

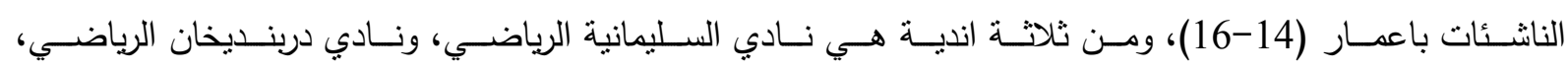

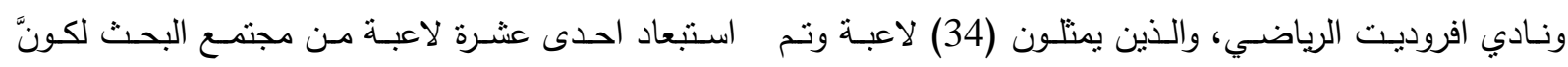

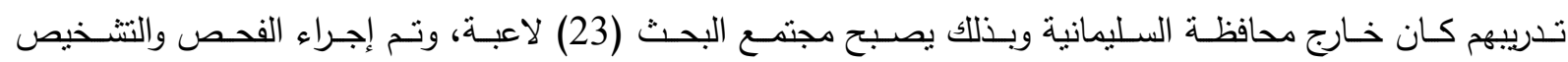

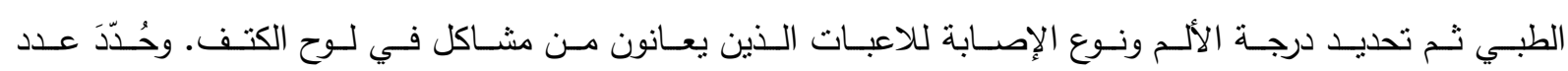

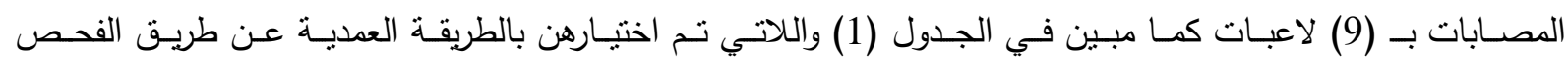

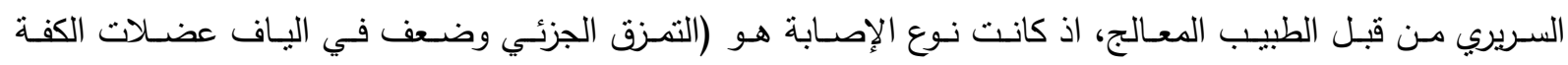

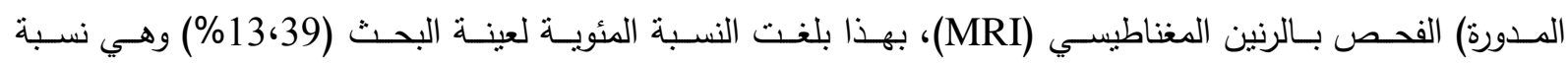

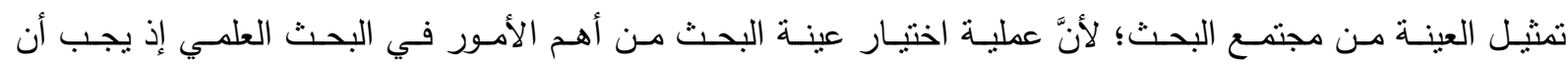

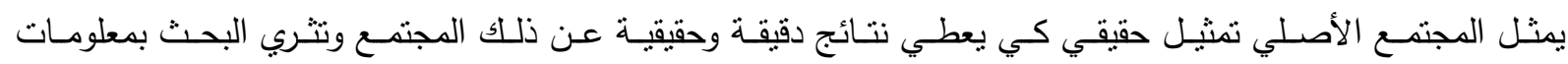

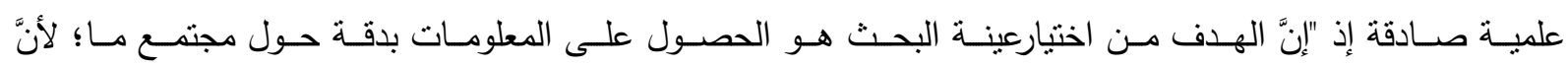

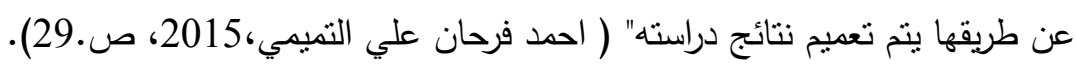


الجدول (1) تجانس عينه البحث في متغيرات السن والعمر التدريبي والطول والوزن

\begin{tabular}{|c|c|c|c|c|}
\hline معامل الأختلاف & الانحراف المعياري & الوسط الحسابي & المتغيرات & ت \\
\hline$\% 3.9$ & .600 & 15.111 & العمر (سنة) & 1 \\
\hline$\% 21$ & .726 & 3.444 & العمر التذريبي (سنة) & 2 \\
\hline$\% 3.6$ & 5.967 & 162.888 & الطول (سم) & 3 \\
\hline$\% 18$ & 10.533 & 58.222 & الكنلة (كغم) & 4 \\
\hline
\end{tabular}

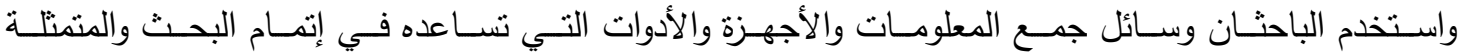
بالمصــادر والمراجـع العربيـة والأجنبيـة وشـبكة المعلومـات الدوليـة والمقـابلات الثخصـية والاتصــالات الالكترونيــة واستمارة التسجيل.

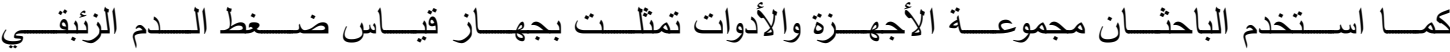

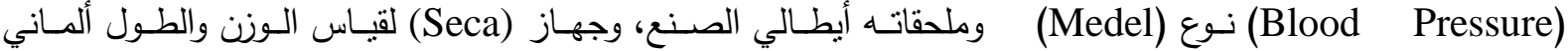
الصنع مودل (M306800) وحبال مطاطية، كرات طبية مختلفة الاوزان بمـا ان الاختبـارات والقياسـات "هـي عمليـة تفاعـل بـين المختبـر والاختبـار علـى بـذل أقصسى جهـد لتحقيـق

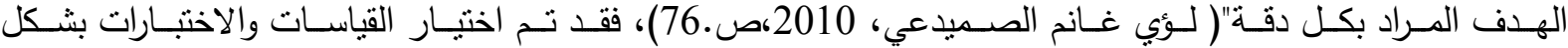

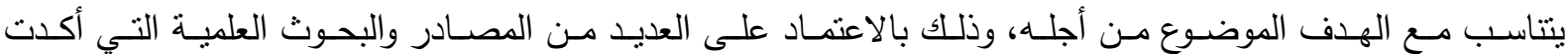

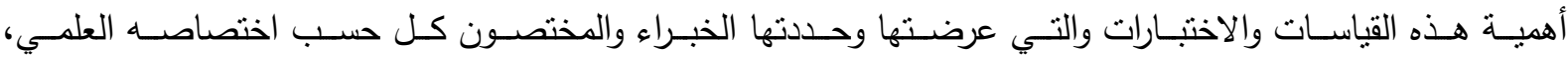
كما تضمنت القياسات والاختبارات كالاتي: القياسـات الجسـمية وشـملت: قيــاس الــوزن (نـزار الطالــب و محمــود الســامرائي،1998،ص.152)، وقيــاس الطول.

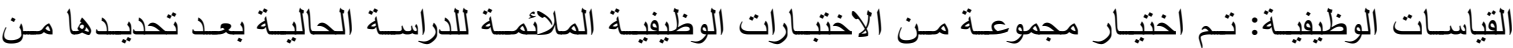

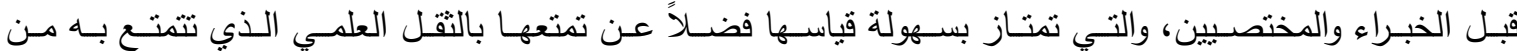
ناحية الصدق والثبات والموضوعية نظراً لكونها قد طبقت على البيئة العراقية وهي:

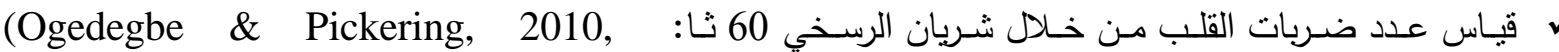

‘P.574-577)

(Ogedegbe \& Pickering, 2010, P.574-577) وقياس الضغط الدموي The Lloydspharmacy Handheld Body Composition ) مستوى نسبة كتلـة الجسـ:

(Monitor التجــارب الاســطلاعية: تعـرف التجربــة الاسـتطلاعية بانهـا" عمليـة اسـتطلاع الظــروف المحيطــة بالظــاهرة التـي يرغب الباحـث في دراستها وهـي الكثـف عـن الحلقـات الغامضــة، وهـي دراسـة تجربـة أوليـة مصـغرة تدريبيـة لتقبيم

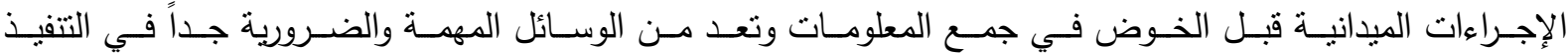

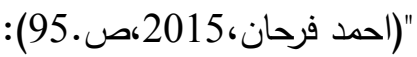

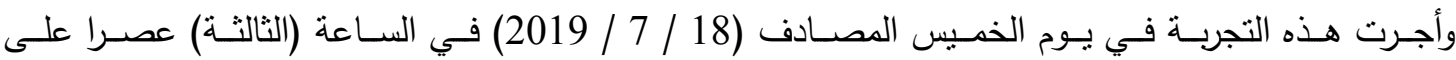
ثلاثة لاعبات من أفراد عينة البحث بمساعدة فريق العمل المساعدوذلك لغرض: معرفة صلاحية القياسات والاختبارات ومدى ملاعمنها لأفراد عينة البحث. معرفة صلاحية الأجهزة والأدوات المستخدمة ومدى صلاحيتها. معرفة وقت الاختبارات وكيفية تقسيم الاختبارات. 
التعامل مع الثروط التي هي من واجبات فريق العمل المساعد.

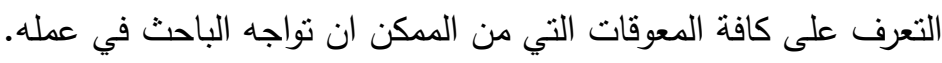

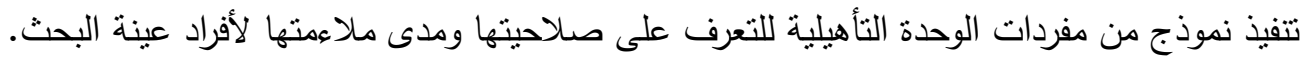

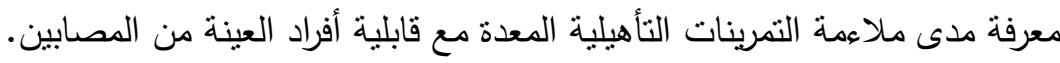

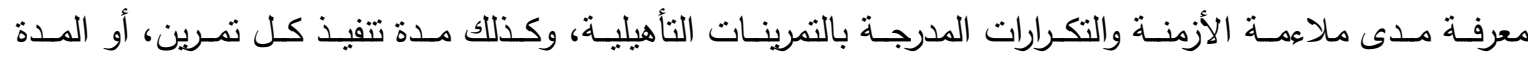

عند تتفيذ مجموعة التمرينات كوحدة تأهيلية.

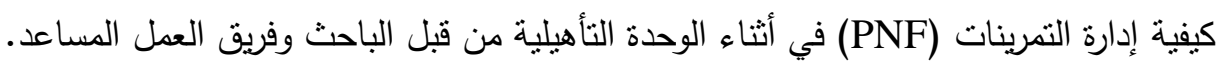

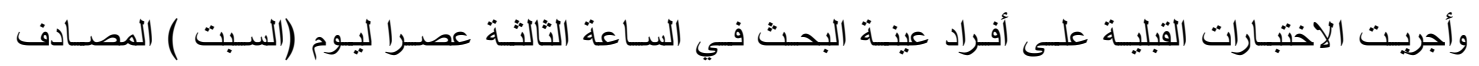

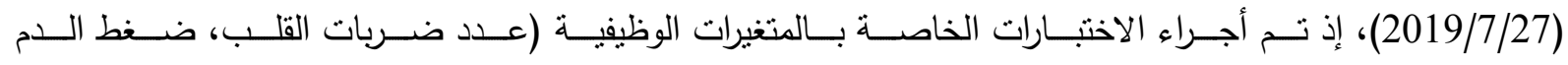

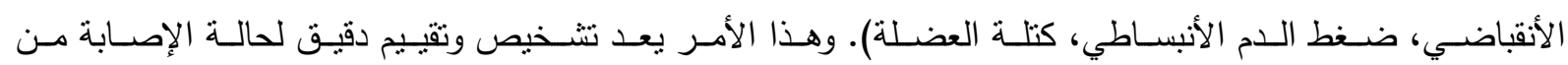

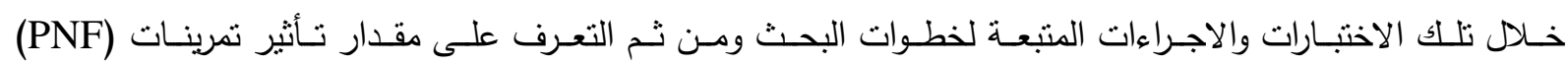
في المتغيرات الوظيفية عند التعرض لأصابة الكفة الدوررة.

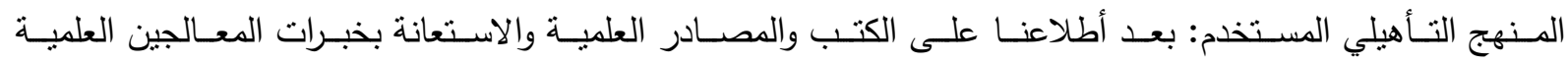

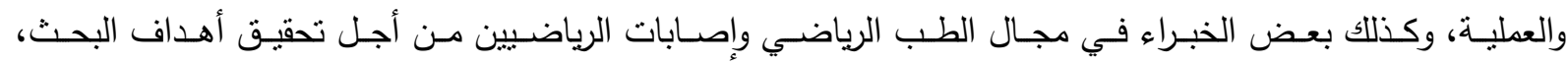

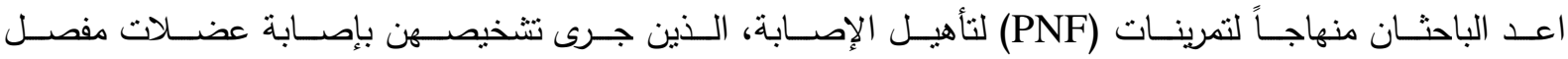

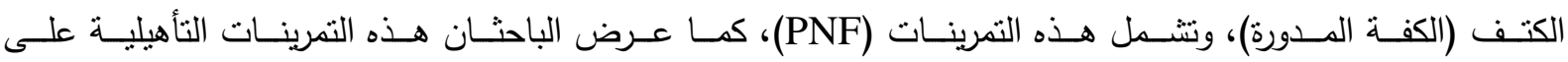

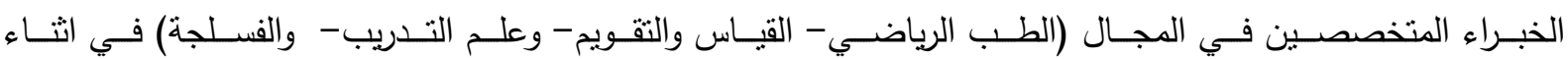
إجراء خطوات البحث. وقد اعتد الباحثان بعض الأسس أنثاء أداء التمرينات التأهيلية وهي:

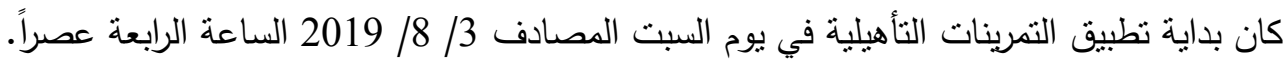

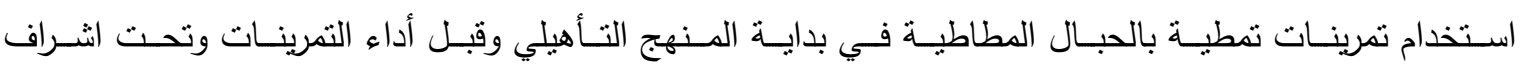
الباحثان وفريق العمل المساعد، إذ كان بتراوح زمنه من (7 د د - 12 د).

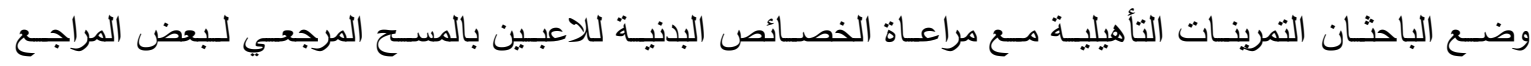

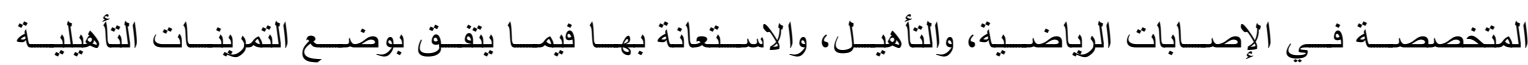
وتحقيق أهدافها.

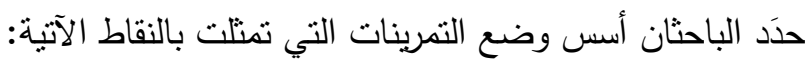

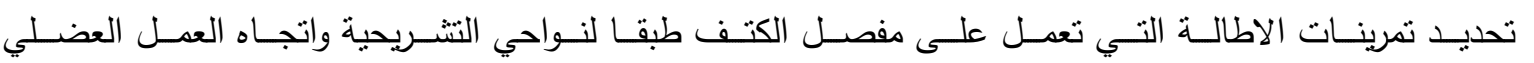
للمفصل. التندرج في النكرار التنوع بالتمرينات.

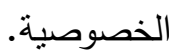
مرونة المنهج التأهيلي وصلاحيته للنطبيق العملي.

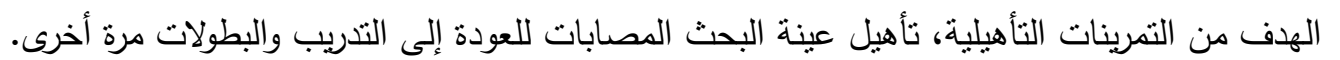

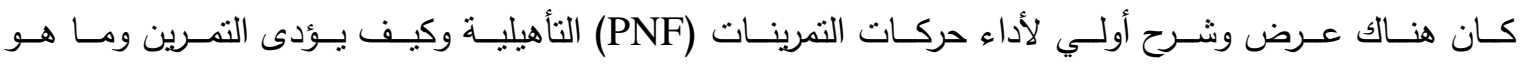
غرضه.

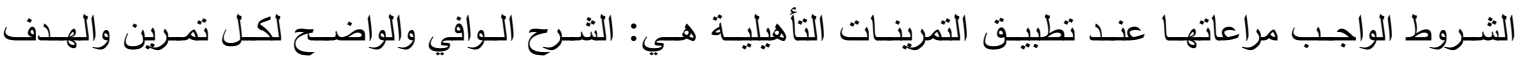
منه حتى يكون اثتراك اللاعب إيجابيا ومراعاة عوامل الأمن والسلامة. 


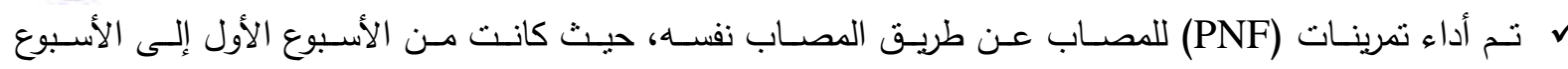

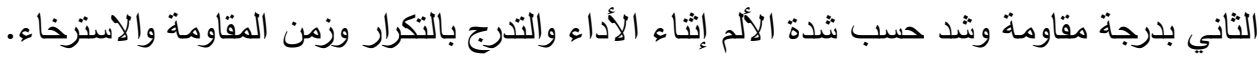

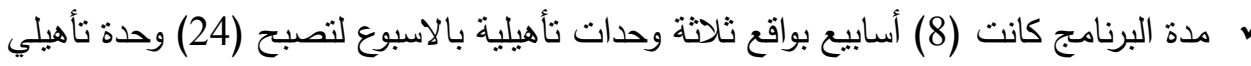

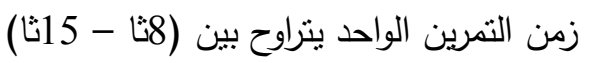

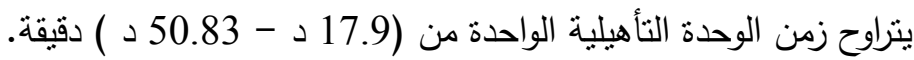

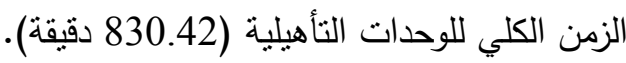

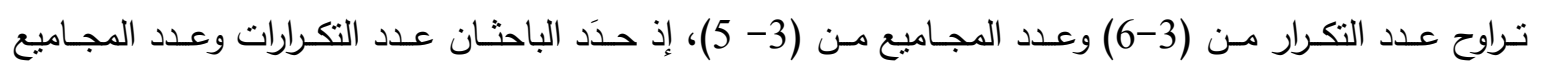

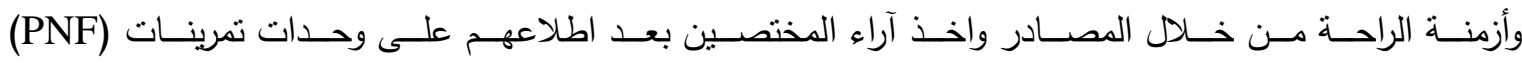

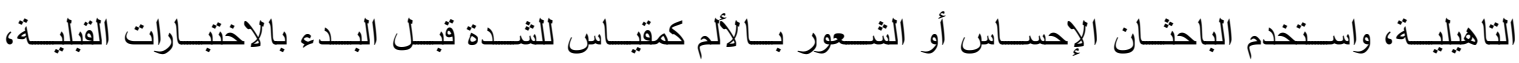

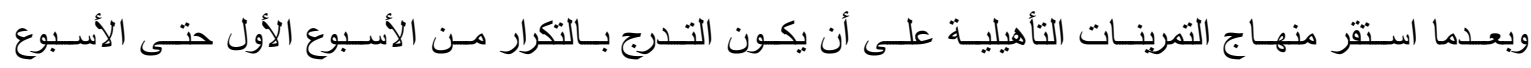

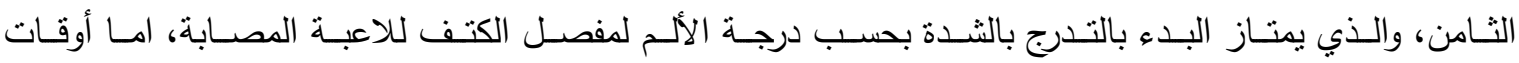

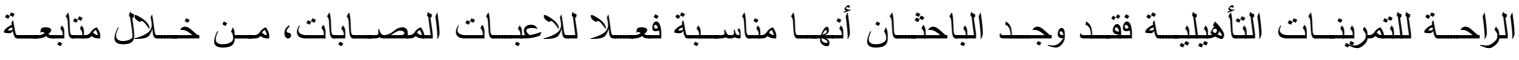

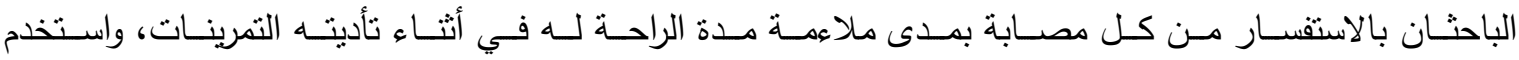

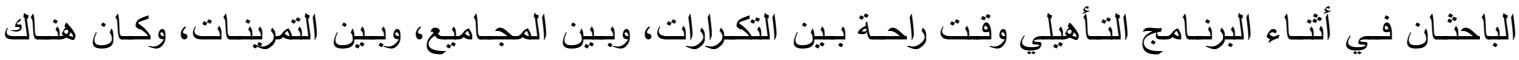

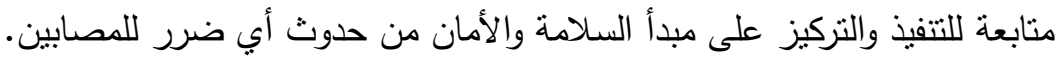

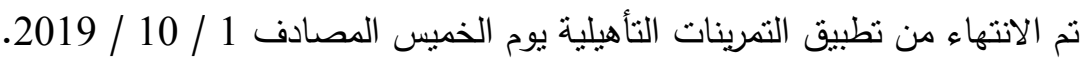

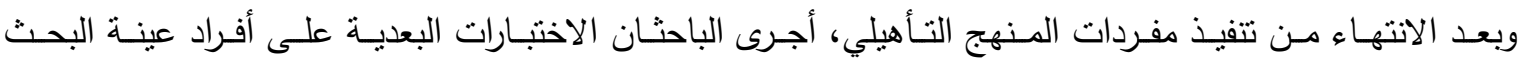

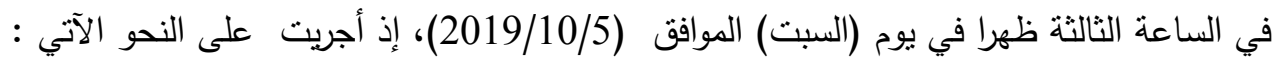

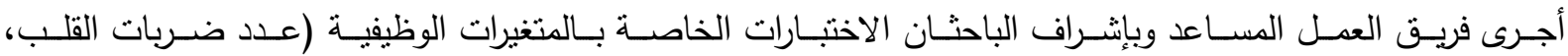
ضغط الدم الأنقباضي ، ضغط الدم الأنبساطي، كتلة العضلة).

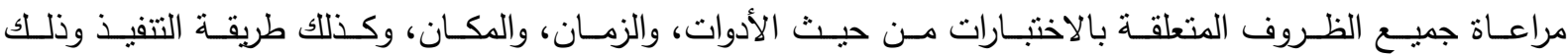
لتوفير الظروف نفسها التي استخدمت في الاختبارات القبلية.

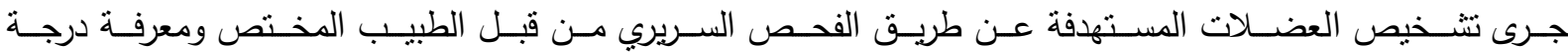

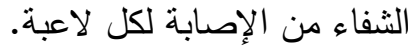

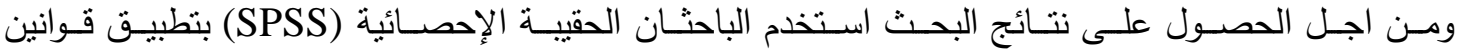

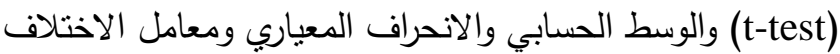

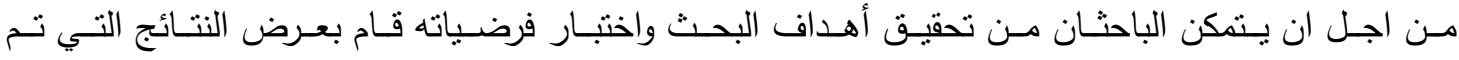

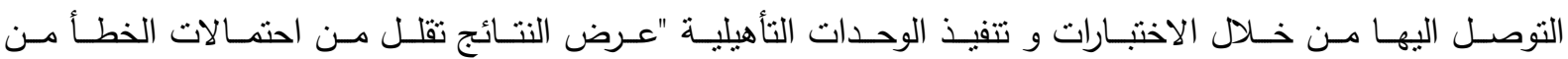

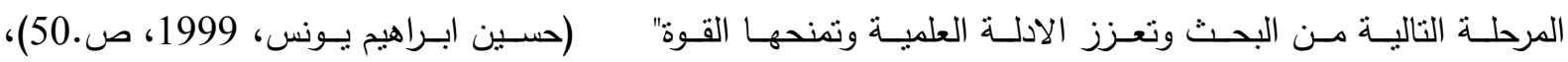

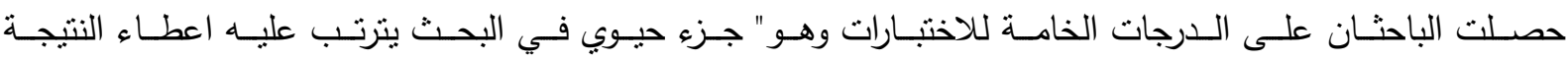

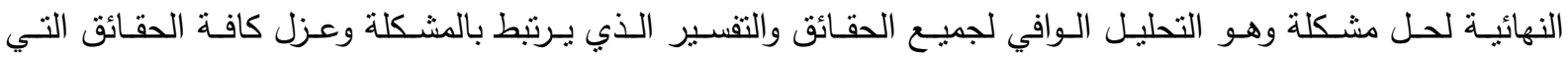

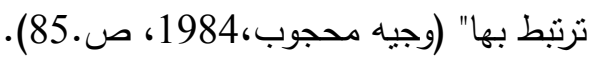

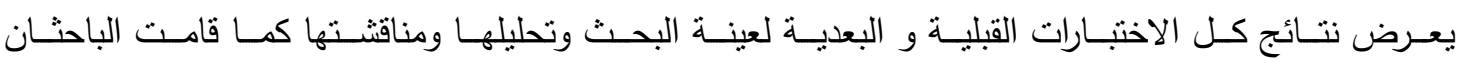

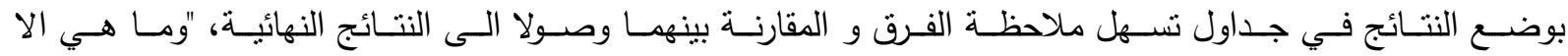




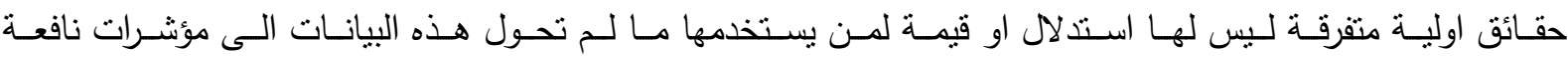
وذات قيمة يعبر عنها بالمعلومات" (نوري الثوك و رافع صالح الكبيسي،2004، ص.93). الجدول (2) يبين الوسط الحسابي والانحراف المعياري وفرق الوسطين والاتحراف المعياري وقيمة (ت) المحسوبة ومستوى الدلالة ونوع الفروق لعينة البحث في الاختبارين القبلي والبعدي لقياس نبض القلب، ضغط الدم الأنقباضي والأنبساطي

\begin{tabular}{|c|c|c|c|c|c|c|}
\hline نوع الفروق & مستوى الخطأ & قيمة ت & $\varepsilon^{ \pm}$ & سَ س & 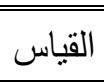 & الاختبارات \\
\hline \multirow{2}{*}{ معنوي } & \multirow{2}{*}{0,036} & \multirow{2}{*}{2,524} & 15,438 & 90,888 & القبلي & \multirow{2}{*}{ نبض القلب } \\
\hline & & & 3,597 & 78,222 & البعدي & \\
\hline \multirow{2}{*}{ معنوي } & \multirow{2}{*}{0.019} & \multirow{2}{*}{2.929} & 12,088 & 136,688 & القبلي & \multirow{2}{*}{ ضغط الدم الأنقباضي } \\
\hline & & & 4,779 & 124,411 & البعدي & \\
\hline \multirow{2}{*}{ معنوي } & \multirow{2}{*}{0,014} & \multirow{2}{*}{3,153} & 4,427 & 91,577 & القبلي & \multirow{2}{*}{ ضغط الدم الأنبساطي } \\
\hline & & & 3,013 & 85,155 & البعدي & \\
\hline
\end{tabular}

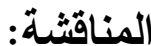

ان الإصـابات رياضية تحدث وبدرجات متفاوتة سواء كانت في المنافسات الرياضية أو في الوحدات التدريبية، مما نستدعي فترة علاج نتقي الرياضي بعيداً عن أي نشاط وتثأثر ذلك سلباً على لباقته البدنية الوظيفية ومستوى انجازه ومسببة بعض المضاعفات التي قد تعيق سير العملية التدريبية وما يرتبط بذلك من تأثنرات وظيفية على الرياضـي، إن الفـرد الرياضــي حينمـا يصـاب يعـاني مجموعـة مـن المعوقـات والتغيـرات مـن الناحيـة الوظيفيـة

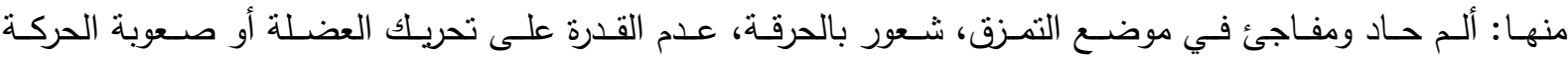

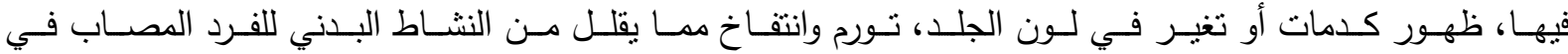

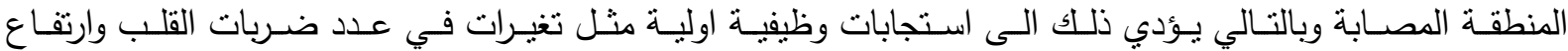
أو انخفاض مستوى الضغط الدموي وغيرها من المؤشرات الوظيفية.

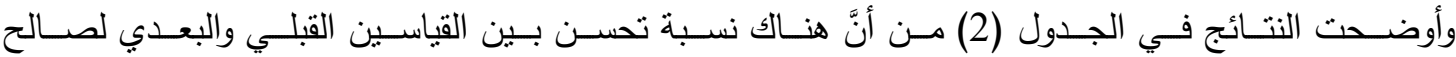
القيـاس البعـدي، ويرجـع هـذا التحسـن إلـى التـأثنير الإيجـابي للبرنـامج التــأهيلي والتـي تتضـــن عمـل المسـتقبلات

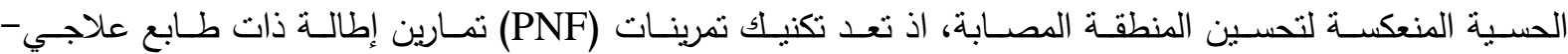

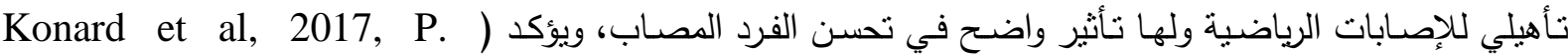
1071) نقلا عن (كاي) أنّ تمارين الإطالة العضلية ومنها (PNF) يقل نسبة تصلب الأوتار و العضلات. ويشبر أيضاً (Pedersen BK and Febbraio ， 2012, p. 457) أنّ تمرينات الإطالة (PNF)

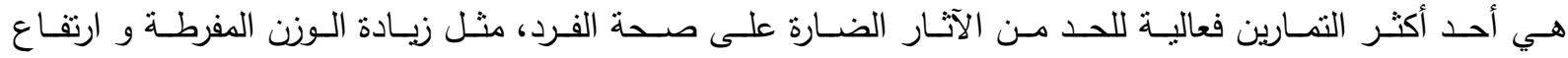

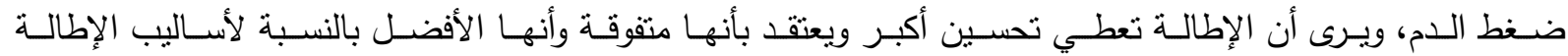

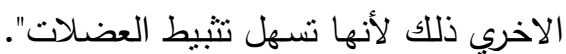

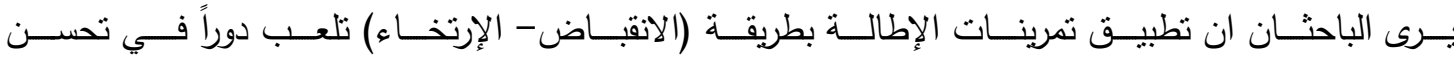

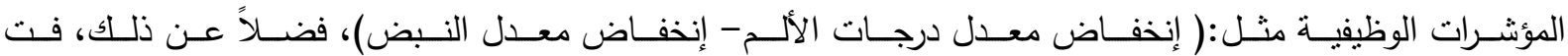

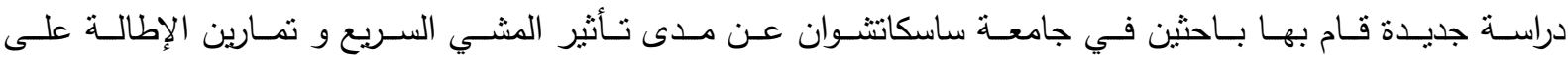

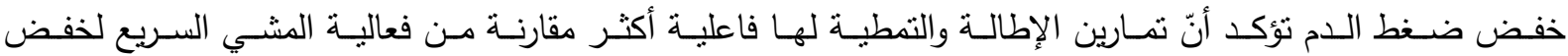

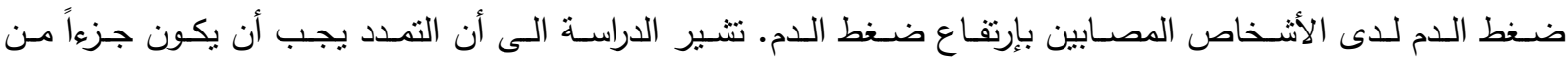
خطة علاج شاملة للأشخاص الذين يعانون من إرتفاع ضغط الدم (Ko et al, 2020, P.21). 


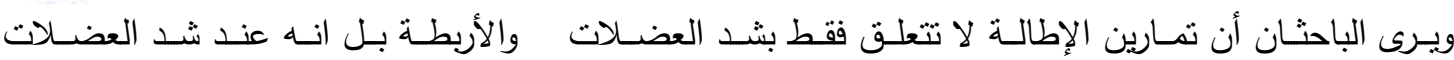

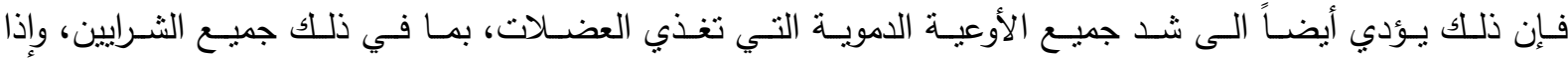

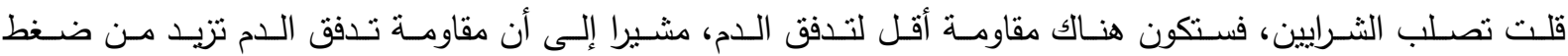
الدم.

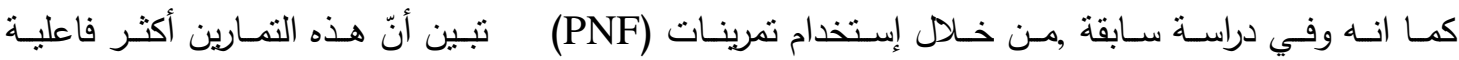

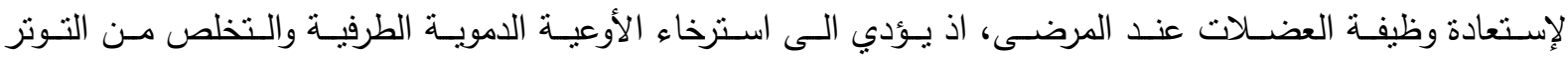

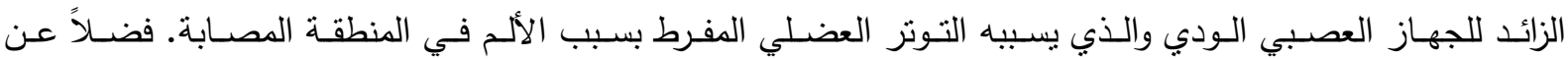

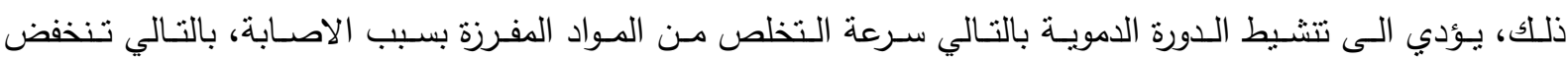
نسبة الالم وعودة ضعط الدم الى حالته الطبيعية بشكل ملحوظ (Morikawa, 1992, P.38).

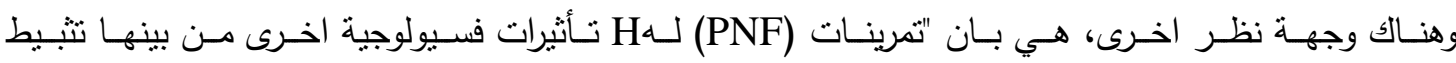

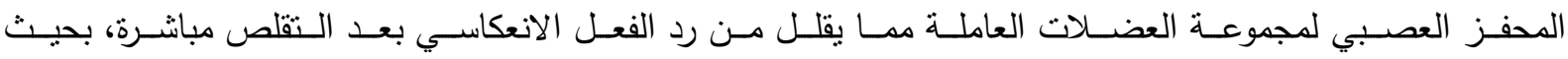

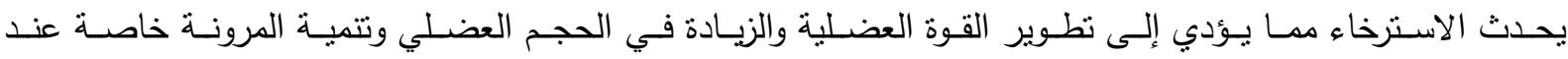

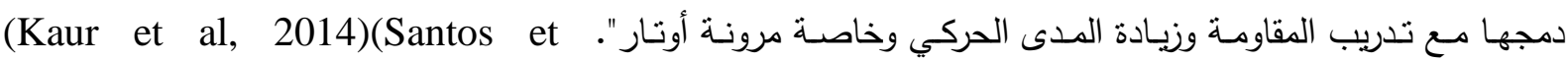
(Paz et al, 2012) al, 2017) (Arazi et al, 2012)

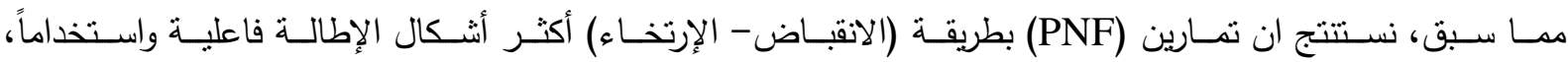
فهـي تلـك الإطالــة التـي تسـتخدم قواعـد وأسـس التحسـس الـذاتي العصبـي العضـلي بطريقـة (الانقبـاض - الإرتخـاء)

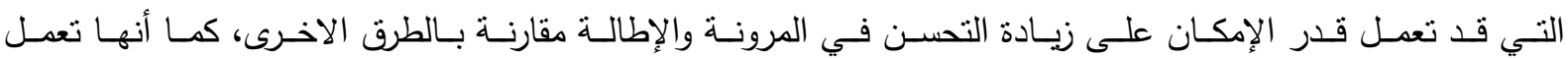

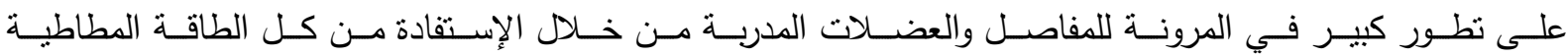

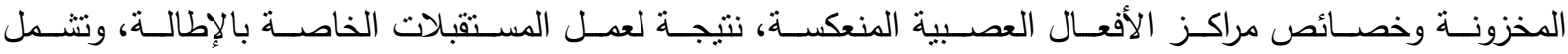

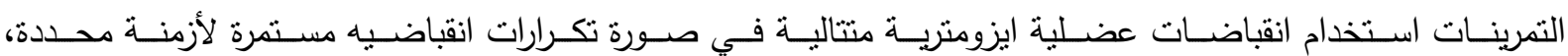

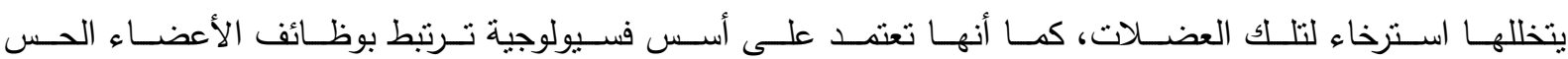

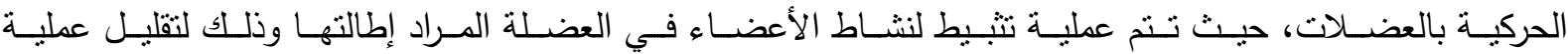

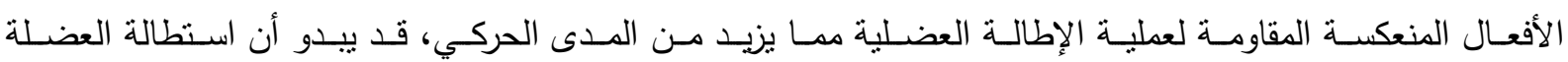

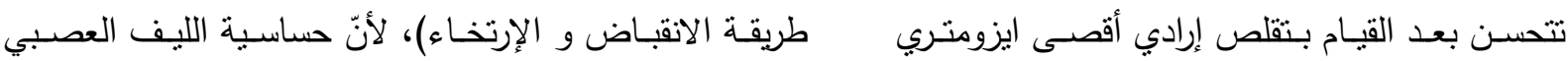

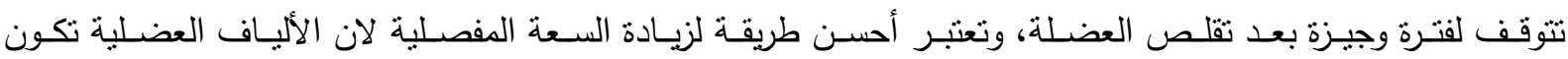
في حالة تمدد نسبي حتى أثثاء التقلص ما يسهل عملية تمديدها بعد ذلك.

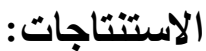

ان تمرينـات الاطالـة العضـلية بتسـهيل المسـتقبلات العصبية (P.N.F) لهـا تـأثنيرا ايجابيـاً في تأهيـل إصـابة التــزق الجزئي لعضلات وأوتار الكفة المدورة وفق المتغيرات الوظيفية.

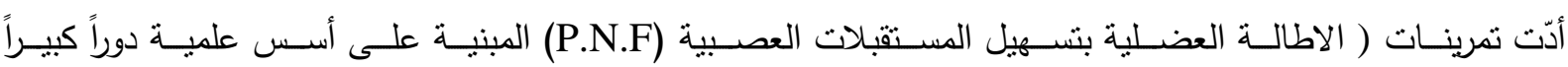
في تحسين المتغيرات الوظيفية المأخوذة لصالح القياس البعدي.

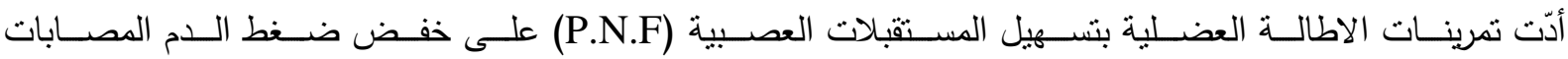
بسبب أصابة الكفة المدورة. 


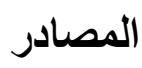

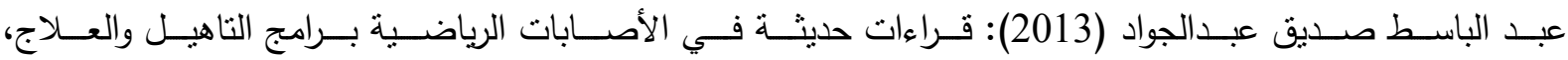
ماهي للنشر والتوزيع، الأسكندرية. سمير الجزار (2014) : العلاج الطبعى والتأهيل للتمزق العضلي، مركز الكتاب للنشر ، القاهرة. محمد قدري بكري: (2000) النأثثر الرياضى والإصابات الرياضية والإسعافات، المؤلف، القاهرة.

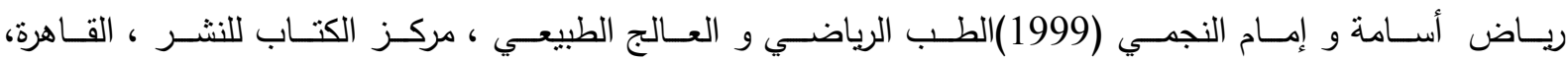
ص ص لؤي غانم الصميدعي • (2010) ، الإحصاء والاختبار في المجال الرياضة ، ط1، اربيل ، ص76.

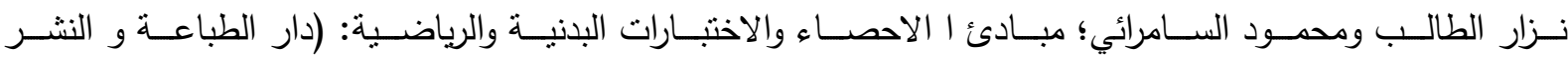
بجامعة الموصل، 1981، ص236-240).

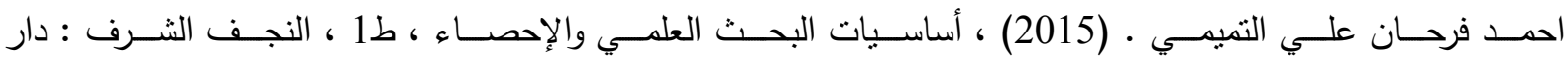
الضياء للطباعة، ص29.

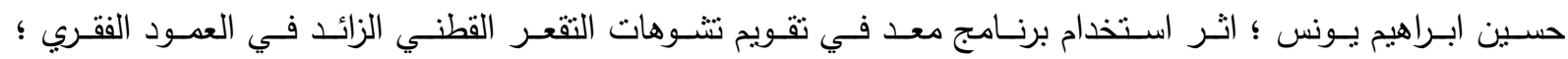

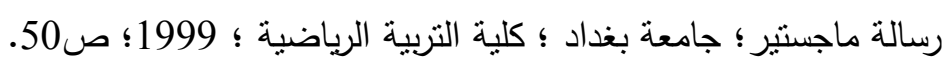

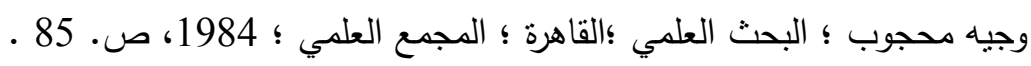

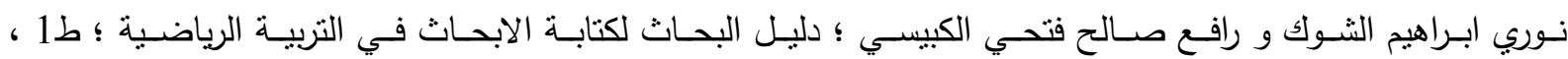
بغداد 2004، ص. الحجار ، ياسين طه (2002) :محاضرات فسلجة التدريب الرياضي لطلبة الدكتوراه، جامعة الموصل.

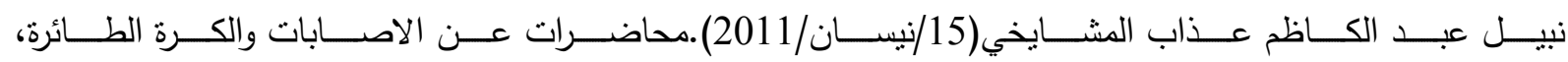
http://www.uobabylon.edu.iq/uobColeges/lecture.aspx?fid=14\&lcid=3879

The Lloydspharmacy Handheld Body Composition Monitorhttps ://manualzz.com/doc/7164038/body-composition-monitor

Pedersen, B. K., \& Febbraio, M. A. (2012). Muscles, exercise and obesity: skeletal muscle as a secretory organ. Nature Reviews Endocrinology, 8(8), 457-465.

Ogedegbe, G., \& Pickering, T. (2010). Principles and techniques of blood pressure measurement. Cardiology clinics, 28(4), 571-586.

Gumina S, Candela V, Passaretti D, Latino G, Venditto T, Mariani L, Santilli V. The association between body fat and rotator cuff tear: the influence on rotator cuff tear sizes. J Shoulder Elbow Surg. 2014 Nov;23(11):1669-74. doi: 10.1016/j.jse.2014.03.016. Epub 2014 Jun 4. PMID: 24906904.

Malina, R. M., Bouchard, C., \& Bar-Or, O. (2004). Growth, maturation, and physical activity. Human kinetics.

Aagaard, H., \& Jørgensen, U. (1996). Injuries in elite volleyball. Scandinavian journal of medicine \& science in sports, 6(4), 228-232.

Adirim, T. A., \& Cheng, T. L. (2003). Overview of injuries in the young athlete. Sports medicine, 33(1), 75-81.

DiFiori, J. P., Benjamin, H. J., Brenner, J. S., Gregory, A., Jayanthi, N., Landry, G. L., \& Luke, A. (2014). Overuse injuries and burnout in youth sports: a position statement from the American Medical Society for Sports Medicine. British journal of sports medicine, 48(4), 287-288.

Antich, T. J., \& Lombardo, S. J. (1985). Clinical presentation of Osgood-Schlatter disease in the adolescent population. Journal of Orthopaedic \& Sports Physical Therapy, 7(1), 1-4. 
Blimkie, C. J., Lefevre, J., Beunen, G. P., Renson, R. O. L. A. N. D., Dequeker, J., \& Van Damme, P. A. S. C. A. L. (1993). Fractures, physical activity, and growth velocity in adolescent Belgian boys. Medicine and science in sports and exercise, 25(7), 801-808.

Bieri, D., Reeve, R. A., Champion, G. D., Addicoat, L., \& Ziegler, J. B. (1990). The Faces Pain Scale for the self-assessment of the severity of pain experienced by children: development, initial validation, and preliminary investigation for ratio scale properties. Pain, 41(2), 139-150.

Mendonça, L. D., Bittencourt, N. F. N., Barreto, R. A., Paiva, T. F., Porto, R. F., Silva, A. A., \& Fonseca, S. T. (2011). Correlation between isokinetic profile and shoulder injuries in male volleyball athletes. British Journal of Sports Medicine, 45(4), 343-343.

Bradley, P. S., Olsen, P. D., \& Portas, M. D. (2007). The effect of static, ballistic, and proprioceptive neuromuscular facilitation stretching on vertical jump performance. Journal of Strength and Conditioning Research, 21(1), 223.

Ko, J., Deprez, D., Shaw, K., Alcorn, J., Hadjistavropoulos, T., Tomczak, C., ... \& Chilibeck, P. D. (2020). Stretching is Superior to Brisk Walking for Reducing Blood Pressure in People With High-Normal Blood Pressure or Stage I Hypertension. Journal of Physical Activity and Health, 18(1), 21-28.

Morikawa, K. (1992). Clinical effect of SUPER LIZER (HA-30). Orie Mad Pain Clin, 22, 37-44.

Kaur, M., Paul, R., Kumar, S., Arora, R., \& Arora, L. (2014). A randomized controlled trial to compare the effectiveness of static stretching versus PNF stretching of hamstring muscles following superficial heat in athletes. International Journal of Scientific and Research Publications, 4(7).

Santos, S., Jimenez, S., Sampaio, J., \& Leite, N. (2017). Effects of the Skills4Genius sports-based training program in creative behavior. PloS one, 12(2), e0172520.

Paz, G. A., de Freitas Maia, M., Lima, V. P., Oliveira, C. G., Bezerra, E., Simão, R., \& Miranda, H. (2012). Maximal Exercise Performance and Electromyography Responses after Antagonist Neuromuscular Proprioceptive Facilitation: A Pilot Study. Journal of Exercise Physiology Online, 15(6).

Arazi, H., Nia, F., Hakimi, M., \& Mohamadi, M. (2012). The effect of PNF stretching combined with a resistance training on strength, muscle volume and flexibility in non-athlete male students. Sport Science, 5(1), 85-90. 